NBSIR 79-1703

\title{
The Timely Development of Environmental, Safety, and Health Standards for Energy Technologies
}

Bruce W. Steiner

National Bureau of Standards

Washington, D.C. 20234

January 1979

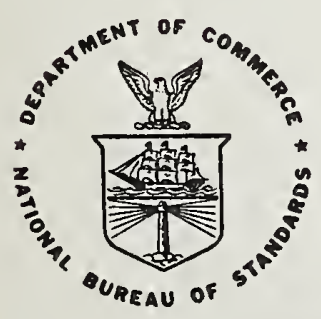



NBSIR 79-1703

\section{THE TIMELY DEVELOPMENT OF}

ENVIRONMENTAL, SAFETY, AND

HEALTH STANDARDS FOR ENERGY

TECHNOLOGIES

Bruce W. Steiner

National Bureau of Standards

Washington, D.C. 20234

January 1979

U.S. DEPARTMENT OF COMMERCE, Juanita M. Kreps, Secretary Jordan J. Baruch, Assistant Secretary for Science and Technology

NATIONAL BUREAU OF STANDARDS, Ernest Ambler, Director 

The Timely Development of

Environmental, Safety, and Health

Standards for Energy Technologies

Bruce Steiner

January 1979 
SUMMARY

Major Changes in Demands on the Management of National

Standards Are Underway

The Department of Energy (DoE) is now being required to provide systematic assurance, that, when new energy technologies are ready for commercialization, their introduction is not held up by: 1) the absence of essential environmental, safety, and health (ES\&H) limits standards, nor 2) an inability to demonstrate compliance with the then existing standard limits. Pressure to implement such a program at the earliest possible time is coming from the Congress, the White House, and the private sector. Simultaneously, the DoE line program divisions are focusing on performance specifications as aids to the systematic stimulation and transfer of technology to the private sector.

The previous responses of other Federal agencies to increased pressures for limits do not provide suitable models for present systems specifications and measurements needs of the Department of Energy. Certain nuclear safety standards, for example, have not won the desired widespread public support in spite of a strong Federal effort to develop a comprehensive set of specified safety standards. Moreover, in the present instance, a highly focused effort similar to the Federal development of more rigid nuclear specifications would not be suited to the commercialization of the far more diverse non-nuclear technologies. Similarly, existing environmental limits do not provide an accepted model. They are widely perceived not to take into account sufficiently 
the costs of compliance. Moreover, environmental limits are frequently imposed too suddenly for the Department of Energy to use them as a basis for long range environmental planning. The following analysis describes DoE activities that would enable the voluntary consensus standards bodies, without substantial change, to respond to the large new demands for ES\&H limits in the effective manner that these bodies have displayed for commercial specifications.

\section{New Pressures Reflect Switch from Passive to Active Role for $\underline{\text { Standards }}$}

An effective response to the new pressures for stronger management of energy systems ES\&H specifications begins with the recognition that the current pressures extend far beyond energy. These pressures have major agency and company implications that will be described. These pressures reflect a widespread desire for national consensus practices to play a new role, one with greatly increased leverage. In the past, specifications in the United States have been developed as a response to needs in existing technology driven by commercial incentives, needs perceived and ranked initially by senior technical managers. Now a new set of new system specifications for various future technologies is being called for. Such specifications will stimulate new technology, guide its development, and optimize transfer within the private sector. 


\section{Anticipatory Mode Imposes Certain Basic Research \\ and Systemic Requirements}

The new role for systems specifications requires that many specific research needs now will have to be anticipated. The execution of this research will have to be closely coordinated with the voluntary consensus standards writing bodies. Both of these changes will affect the research community far beyond the traditional purview of commercial product specifications.

In order to develop advanced systems specifications in time for the commercial introduction of technologies, the system of standards will need to fulfill certain new criteria. First, the system will need to anticipate technical problems in an orderly comprehensive fashion. Second, the system will need to establish priorities for the importance of specific technical problems and related product specifications and measurements and incorporate requirements for necessary lead time. The system will need to assign formal responsibility for the essential functions. Finally, it will need to assure funding and implementation, and to monitor progress.

At the same time, any specifications development must continue to fulfill previously established criteria. The system and the resulting specifications must be compatible with primary agency and private sector responsibilities. Moreover, specifications development must continue to accommodate the responsibilities of other Federal and private agencies. The resulting specifications must also be economical. These results will most readily be achieved through an open consensus process by mutual cooperation. 


\section{$\underline{\text { Required Provides Strategic Tests }}$}

Present procedures for the establishment of voluntary consensus specifications excel at the two national functions that they were designed to perform, namley: 1) the development of an educated consensus among interested parties, and 2) nationally recognized specification writing. These functions are performed with economy consistent with the achievement of real consensus. The new role for specifications, however, requires a process with an expanded set of functions. Four functions are now essential on a national scale; six more are needed in each Federal agency or company with a major interest in anticipated standards for any given technology. Performance of all ten functions is necessary if the standards development process is to meet the goals established by the Department of Energy.

The first of the four national functions is clearly 1) the voluntary consensus standards writing process. This is the keystone of the present system and must be preserved. The institutional functions described below are designed to facilitate the development and use of voluntary standards by both public and private institutions. 2) Federal specification development is a second national function well established in the technological sector. Current trends toward utilization of the voluntary consensus standards system by the Federal specification process can strengthen the execution of both of these functions. To these well established national activities need now be linked 
additional functions.

3) Information on the existence of standards and those under development will be increasingly important in avoiding duplication and confusion. 4) Establishment of interinstitutional collaboration is also crucial in order to provide for collaborative standards development under special circumstances.

In addition to these four national functions, six institutional functions now are essential for anticipatory systems standards development. These six are needed by each closely affected Federal agency and major company. Three of these six functions provide essential internal institutional coordination, and the remaining three provide essential support. 1) The first of the six, management of institutional standards development must be designed to assure the effective implementation of the other five institutional functions. The second, establishment of institutional priorities is critically important. 3) The third, a mechanism for institution-wide technical decision, is also critical for assurance of the fulfillment of institutional goals, such as environmental, safety, and health preservation, consistent with economical and technical considerations.

4) The fourth function is technical support for "limit" standards, those standards that limit technical system performance. 4) Closely associated with this, but distinct from it, is the fifth function, technical support for "compliance measurements" standards, those measurements that provide for evidence of compliance with "limit" standards. 6) Finally, effective execution of all of the above functions will require the sixth function, standards development tracking within each affected institution. 
Needed Functions Require Agency Strategy with Mixture of

\section{Internal and External Elements}

Several specific strategic agency options may be considered for the development of the newly required functions: 1) complete agency responsibility for standards centralized in one part of each agency; 2) total decentralized delegation of standards responsibility to technical divisions; 3) total delegation of standards responsibility to another agency; 4) a mixture of the preceding elements. The first approach would not provide for adequate technology division participation nor for effective participation in nationwide voluntary standards writing bodies, essential to nationally recognized documentation. The second, totally decentralized course would not provide for an institutional, "cross cutting" Departmental approach, which is also essential. The third approach lacks all of these essential elements: technology division and ES\&H participation as well as the national forum presented by consensus bodies. Only the fourth option provides mechanisms for all required functions through participation by all essential parties. A plan establishing these mechanisms in their simplest form has already been submitted to DoE. This plan calls for just such a mixture of responsibility. The next step is to achieve a DoE-wide consensus on:

1) long term systems specifications development goals, and 2) short term specifications development objectives. 
SUMMARY

TABLE OF CONTENTS

I. CHANGE IN DEMANDS PLACED ON THE MANAGEMENT OF STANDARDS

A. Environmental, Safety, and Health Standards.......... 1

B. Technology Specifications.................... 2

C. The Specifications Desired .................... 2

D. Previous Institutional Response................. 4

II. SWITCH FROM PASSIVE TO ACTIVE ROLE FOR STANDARDS..........

III. IMPLICATIONS FOR RESEARCH AND THE DEVELOPMENT OF STANDARDS...

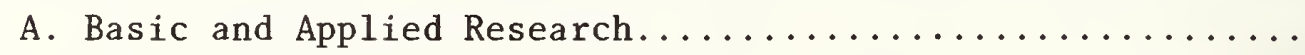

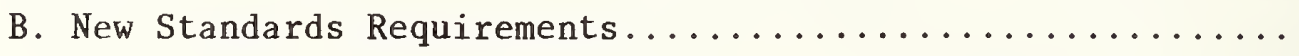

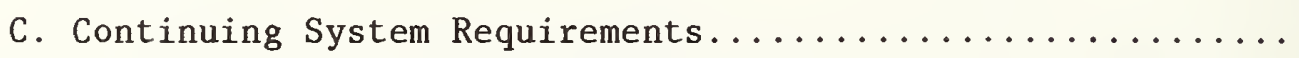


IV. CHARACTER OF PRESENT STANDARDS DEVELOPMENT............ 8

A. Voluntary Standard....................... 8

B. Federal Regulations \& Specifications................ 9

C. Funding \& Priorities...................... 10

D. Technical Support....................... 11

E. Fulfillment of New Requirements................ 12

V. FUNCTIONS NOW REQUIRED ........................ 13

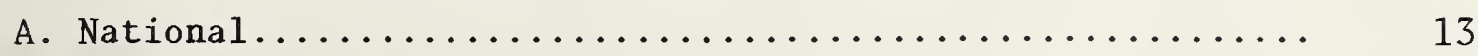

1. Consensus Generation...................... 13

2. Specification Writing.................... 13

3. Standard Information...................... 14

4. Interinstitutional Collaboration............... 14

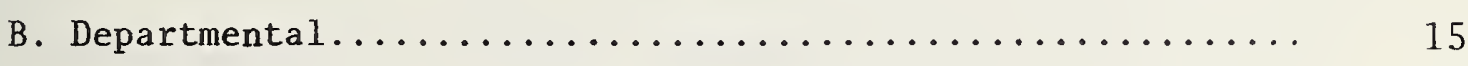

1. Management of Standards Development.............. 15

2. Priority Establishment..................... 16

3. Technical Decision....................... 17

4. Technical Support for Limit Standards.............. 17

5. Technical Support for Compliance Measurements Standards.. $\quad 18$

6. System Tracking........................... 20

VI. AGENCY STRATEGIES FOR THE PROVISION OF ESSENTIAL

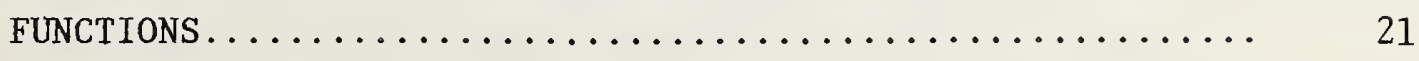

A. Provision of National Functions.................. 21

B. Provision of Agency Functions.................. 22 
1. Coordination.

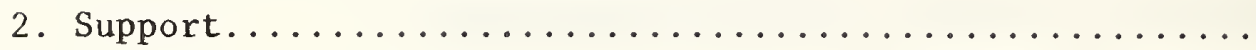

C. Summary.

VII . CONCLUSIONS.

VIII. REFERENCES. 
I. CHANGE IN DEMANDS PLACED ON THE MANAGEMENT OF STANDARDS

\section{A. Environmental, Safety, and Health Standards}

The Department of Energy is being required to provide assurance that new energy technologies will meet national limits established by the time these technologies are introduced commercially. In the area of the environment safety, and health, pressure to do so is coming from Congress (1), from the White House (2), and directly from nongovernmental groups (3). The source of this concern was the absence of systematic planning for the benign operation of energy technologies, both present and future. The new Department is under strong pressure not to depend exclusively on Federal regulatory agencies for systems specifications planning.

The Department of Energy Division of Operational and Environmental Safety (OES) therefore has commissioned a plan for the development of all critically important environmental, safety, and health (ES\&H) standards (limits and specifications). This plan is to outline procedures to assure that, when new technologies are ready for commercialization: 1) all necessary ES\&H standard limits will be in place in the private sector; and 2) the means for demonstrating compliance with these standard limits will be available also in the private sector. 


\section{B. Technology Specifications}

In the area of improved technical performance, standard specifications are also receiving attention from DoE technical divisions as vehicles for stimulating technical innovation and for the transfer of technology to the private sector. For example, new technology codes and standard specifications are being developed for solar heating and cooling, conservation, fossil energy, and photovoltaic energy. Why have this interest and activity in standard specifications suddenly expanded, and what range of responses would be effective? The considerations in the evolution of the DoE plan apply also to other institutions, public and private, faced with the growing implications of standards.

\section{The Specifications Desired}

The codes and standard specifications most generally desired may be viewed as nationally accepted practice (4). Interest in them is based primarily on the fact that they are widely "accepted". This recognition is derived either: 1) from the consensus achieved in voluntary standards writing bodies or 2) from the act of establishment of governmental regulations and specifications (5).

The growing desire for both types of standard specifications, voluntary and governmental, is based on several distinct ramifications of the acceptance process. Of primary importance to the general public and to industry is the formally recognized standing of such 
specifications. Moreover, standard specifications are perceived by the public to provide stable performance guidelines, although this varies greatly with the particular standards. For the technical manager, standard specifications offer nationally recognized levels of acceptable performance and hence reduce the liaibility for technical performance equal to or within the agreed limits. Standard specifications thus represent an advance agreement on what constitutes acceptable performance. The basic importance of a properly functioning set of standard specification limits however, both for the public and for the manager, is twofold. Both the development and the ultimate performance of the system covered by specifications are frequently more predictable than for a comparable system developed in the absence of national participation. Moreover, difficulty in the establishment of standard specifications may serve advance notice of deep-seated difficulty in the development or operation of a particular system. The standard specification development process itself thus can serve as a technical early warning system.

The most prominent difficulties in the development of standard specifications also are related to the procedure for gaining their acceptance. The process of acceptance necessarily involves all concerned individuals and institutions. Such a process is intrinsically a complex and lengthy one. The complexity and length imply, moreover, that the process can be an expensive one. This is true particularly, as we shall see, where one purpose of the standard specification is to stimulate the development of a given technology that lacks a proven basis of experience. 


\section{Previous Institutional Response}

Before undertaking the development of a totally new ES\&H standard specifications plan, we reviewed as potential models previous institutional response to systematic requirements for specifications. The nuclear system could conceivably furnish one such model. However, nuclear limits have been prepared primarily to embody and promulgate homogeneous, Federallydeveloped technology. The current DoE mission, by contrast, is to stimulate the private sector development of heterogeneous technology ("energy options") and to support them with viable private sector standard specifications.

The development of environmental control limits also was not viewed as a suitable model. Industry has displayed widespread concern that the resulting limits are severely uneconomic. In any event, they are being imposed with insufficient advance notification to serve as a basis for long range planning by others. $(6,7)$

II. SWITCH FROM PASSIVE TO ACTIVE ROLE FOR STANDARDS

The traditional voluntary standards writing system has been developed to respond to technical problems arising in industry and commerce (8). The widespread use of the system has resulted from its 
responsiveness to acknowledged industrial and commercial concerns. When problems arose, the system has not acted until it achieved a consensus. This consensus has contributed greatly to the probability of compliance.

The recent pressures for systematic standard specifications management reflect the evolution of the following challenging roles for such activity. Standard specifications are now being called for, not only to ameliorate specific recognized problems, but also to stimulate technical innovation for new technologies and to control the course of technical innovation and performance for, e.g., the protection of the environment. In these cases, anticipation of technical performance is a prerequisite. This anticipation is a new requirement. It represents an expansion of the standards writing system from one based previously on well-established experience to one that must increasingly attempt to anticipate problems and provide the necessary experience. Such a system will exercise far greater leverage on technical development than that of traditional standard specifications. Any procedure designed to support this new role successfully must display a substantially expanded set of characteristics. We now turn to these new requirements which must be met if standard specifications are to be in place when needed.

III. IMPLICATIONS FOR RESEARCH AND THE DEVELOPMENT ÓF STANDARD

\section{A. Basic and Applied Research}

The new anticipatory role for standards implies the need both for standards-related research (9) and for its coordination. An evolving 
standards system will require much closer interaction between it and the research stages of the technology with which it is associated than has previously been necessary. Joint priorities for research and standards will be called for in Federal agencies, as has already happened in the private sector (3).

\section{B. New Standards Requirements}

Identification of the critical characteristics of new standards development will provide a basis for evaluating tho ability of current practice and any proposals to meet the new needs:

o Standards development must first of all be anticipatory. It must embody mechanisms to anticipate the need for standards before this need becomes critical.

o The development must be comprehensive. That is, it must provide assurance that needs for important standards will not be overlooked.

o The development must incorporate priorities. In the past this aspect has been handled primarily outside of the voluntary standards writing system. 
- The development must allow for an adequate amount of lead time. The normal standard development process depends upon the existence of data that form the basis of agreement. Where the specifications are anticipated, the research leading to these basic data will also need to be anticipated in a timely fashion.

- The preceding characteristics require the assignment of specific responsibility for various operational activities necessary in the development of a standard (Chapter $\mathrm{V}$ ).

o This above responsibility will necessarily extend ultimately to funding and implementation of general technical support for the development of specific standard.

- Finally, progress in the development of standard will need to be monitored by the primary agency if technology commercialization schedules are to be met.

\section{Continuing System Requirements}

In addition to the characteristics just enumerated, the strengths of present standard development will have to be maintained: 
o Close collaboration with the program organizations must be maintained. They will continue to be a focus for major responsibility for new standard.

o At the same time, the resulting standard specifications will need to be compatible with responsible public concern and with appropriate standards of the agencies charged with public environmental, health, and safety responsibilities. Ultimately standard specifications will not be viewed as adequate if they are not socially accepted.

o Finally, the standard specifications will not be successful if they are not economical to implement, a criterion that will be achieved if the development process continues to include strong industrial participation.

IV. CHARACTER OF PRESENT STANDARDS DEVELOPMENT

A. Voluntary Standard

Most voluntary standards writing organizations are composed of technically homogeneous committees that consist of concerned individuals and institutional representatives. These committees examine the need for given national standards practices, develop a strategy for their 
attainment, and work together until a consensus is achieved on their content. Additional review and consent is usually furnished by others in the committee's parent organization. Finally, the approved document is registered with the American National Standards Institute.

This process derives its strength through the development of a consensus among concerned parties. In addition to the tradition of use of the consensus process in the development of standard practices and procedures in this country, there are very strong technical reasons for the development of a consensus. Since a standard specification or measurement is generally designed to have a broad impact, the full breadth of its impact should be taken into consideration in its development. Consideration by all affected parties is assured by an effective consensus process. It is thus desirable that this system be strengthened.

\section{B. Federal Regulations $\underline{\&}$ Specifications}

With the recent growth of governmental activity, especially in dealing with ES\&H issues another path to standards has been used increasingly in recent years: direct governmentally established limits. These standards rest not upon consensus but upon legislated responsibility. Public views are frequently incorporated through the publication of an "Advanced Notice of Proposed Rule Making" in the Federal Register with the accompanying request for comment. But the 
ultimate responsibility for, and standing of, such a standard rest on governmental authority. The trend now for Federal agencies is to participate in the writing of voluntary consensus standards and toward the parallel development of Federal regulations, and specifications and voluntary specifications. That is, Federal regulatory bodies are now attempting to assist the development of voluntary national standard practices instead of issuing differing Federal regulations and specifications. This evolution in recent years, is contributing to the establishment of scientific data as the basis for national standard specifications.

\section{Funding $\underline{\&} \underline{\text { Priorities }}$}

A chief characteristic of the current development of voluntary consensus standards is a broad base. Many participants are involved in roles subsidiary to other responsibilities. Authority is not focused on a single institution, although general coordination is provided by organizations such as the American National Standards Institute and the American Society for Testing and Materials. Participants are funded by their own participating institutions. This decentralized support constitutes a major strength of the present system. It provides for the establishment of priorities informally through the breadth and depth of the interest in the development of particular specifications. Standards documents are not developed if they are not strongly desired by those contributing to their generation. 
However, it is possible that standards may not be promulgated on occasion even though they may be of high priority, if a consensus cannot be reached on their content. Conversely, in special cases where the Federal Government has recognized the strong need for the accelerated development of standard, it has supported a concerted effort. This has occurred for example in the development of nuclear technology. The cost of developing nuclear materials specifications, like the technology itself, was born largely by the Federal Government (10).

The requirement for strong support before the development of a standard specification or measurement is undertaken is vital to the voluntary standards writing process as it exists. However, if funding of data as the basis for environmental, safety, and health limits is not available from the private sector, it is clear that procedures for the establishment of priorities and for funding will have to receive immediate attention by the responsible agency.

\section{Technical Support}

The actual development of a standard specification or measurement procedure, either through the voluntary standards process or as a Government regulation/specification, has depended on the accumulation of scientific data through reliable procedures. Specifications have usually not been contemplated until a basis of reliable data has been laid. In the traditional operation of the standards development system, that is, 
a standard typically codifies existing technical practice. Major additional technical support, therefore, has not been necessary since the critical information typically exists. Now, however, if standards are to be generated in anticipation of technology, or parallel with its development, the necessary research will have to be anticipated and undertaken deliberately in order to obtain basic data. Such new activity will require the establishment of new institutional mechanisms, as agencies with the obligation to develop or control technology are beginning to conclude.

\section{E. Fulfillment of New Requirements}

A comparison of the characteristics of present standards development with the new and continuing requirements shows the importance of continued strength in the voluntary consensus standards and Federal standards processes. They are a key link with the private sector and the ultimate standard specification implementation. To these cornerstones must now be added additional functions so that the entire development will have all characteristics now required. 
V. FUNCTIONS NOW REQUIRED

\section{A. National}

\section{Consensus Generation}

The effectiveness of all standards is closely correlated with the degree of participation and consensus among those most affected. The voluntary standards groups have achieved this important mutual accommodation with great dedication for many years. They will continue to provide key elements in the standards development process. Indeed, any successful plan for agency-wide or company-wide standards development will depend heavily on close cooperation with existing voluntary standards groups.

\section{Specification Writing}

The development of Federal specifications is undergoing change as the recognition of the importance of mutual accommodation increases. This contribution to specification writing is thus being amplified. The process nevertheless is being performed with considerable skill. Dramatic change in the mechanisms for the preparation of specifications is not foreseen. 


\section{Standard Information}

The development of new standards must take into account existing voluntary standards and governmental regulations that are already in use as well as those that are being developed by other agencies. The length of time required for the development and field use of a standard makes the latter category particularly important during the current period of rapidly increasing standards development. An information system that provides information on such activity will avoid substantial duplication of effort. Since the total price tag of a single typical standard falls between $\$ 200,000$ and $\$ 20,000,000$, substantial savings can be made with such information. At least as important as the monetary saving, is the clear desirability of coordination of specific standards interests by various agencies so that the utility of a single new standard will be as broad as possible.

\section{Interinstitutional Collaboration}

Rarely if ever can the functions of a given agency or company be executed in the absence of consideration of the responsibilities of other agencies. Particularly in the field of environment, safety, and health, the views of several agencies must be taken into account. The establishment of priorities by one agency will be carried out most effectively and with least question if other agencies, public and private, have the opportunity to comment on priorities while they are being formulated. 
A second role for interagency coordination, in addition to the establishment of priorities, is the cooperative modification of regulations and specifications already promulgated by other agenices. Where information that has come to light since the development of another agency's regulation or specification indicates that reconsideration is in order, a new standard development effort may clearly be more successful if undertaken jointly by both agencies.

\section{B. Departmental}

1. Management of Standards Development

The development of standards is necessarily a lengthy process because of the large amount of convincing data that must be obtained. It may take as long as twenty years (8). The development now required differs in two important respects from traditional standards development. First, it must anticipate the need for specifications and all that that implies. Second, it must develop standard specifications and measurements in a routine fashion at a substantially accelerated rate. Both of these differences require that: 1) strong, technically credible leadership be exercised by the agency or company with a strong interest; i.e., it must have strong standards management, and 2) this leadership be exercised through the institutionalization of other 
critical functions. Each of these functions can be performed effectively only by those with appropriate expertise and responsibility. It is, therefore, necessary that responsibility for each function be delegated to a distinct internal or external organization, and perhaps to two or three separate institutions. Although such designation of organizations may seem to some a large step to take, the result can be a relatively simple structure that indeed can be managed in an effective manner. Moreover, an explicit allocation of responsibility will permit the entire comprehensive standards development effort to be coordinated by a small but expert central staff.

\section{Priority Establishment}

Because of the length of time and the expense involved in the standards development process, on the one hand, and the consequences of failing to develop adequate standards, on the other hand, the establishment of priorities is critical. There are really two separate levels of priorities that must be established and executed. The first is the establishment of the most critical issues to be addressed. In the areas of environment, safety, and health, this step involves specific hazards identification and priority establishment. The next level is the selection of those specifications that should be developed first and the assignment of priorities to each for development. The establishment of suitable priorities at both levels requires agency-wide participation in order to assure both comprehensiveness and adequate consideration of programmatic factors. 


\section{Technical Decision}

Certain technical decisions on standards that must be made by the agency or company, although basically technical in nature, will be controversial because of conflicting or insufficient information. One example is the decision in a given instance whether or not to develop a voluntary consensus standard specification, a Federal specification, or both. Another is the review of field tests and evaluations and the related decisions whether or not information in hand provides an adequate basis to proceed with standards development.

The simplest reliable approach to the evaluation of compliance involves a comparable, but technically and administratively distinct, technical decision on the adequacy of the compliance data obtained. The differences between this and the standards development decisions are sufficiently great that two distinct activities are called for, one for technical decisions related to standards development and a second for technical decisions related to evidence of compliance.

\section{Technical Support for Limit Standards}

There are two basic kinds of standards that are needed in most standards systems: 1) "limit" standards, which define acceptable limits to system performance and design, and 2) compliance measurement standards, which define the methods for demonstration of compliance with "limit" standards. The development of "limit" standards requires 
knowledge of system performance under given conditions and of the effect on people of possible changes in the environment. This knowledge requires at a minimum certain technical ability, technical background, and familiarity with recent developments in specific fields. Where technology is pushing the state of the art, laboratory work will also be required.

Two formal kinds of technical services will be required now to support the development of new standards. The first is independent technical consultation during the process of decision making. Such consultation will be especially important where the inherently lengthy process must be shortened substantially. The second service is the development of technical information to support specific standards. The former type of service will be technically broad and continuing, while the latter is a series of separate efforts, each highly focused in technology and in time, a "batch" process. Sources of funding of these two types of services will differ in a manner corresponding to those differences. That is, the general function would naturally be supported on an agency-wide basis, while the focused efforts would be more closely coupled to specific technologies.

5. Technical Support for Compliance Measurements Standards

The Compliance Measurement Standard Technical Support function considered here is similar conceptually to Limit Standard Technical Support described in the preceding section. Both require major 
continuing laboratory support with a wide range of expertise. Both must have a broad, basic component and a more highly focused component addressing a series of specific standards.

There are two important distinctions between these support functions, however. In the first place, the technical expertise required is quite different: While Limit Standards Technical Support requires biologists and structural engineers, Compliance Measurement Standard Technical Support requires measurement experts, those who know, or can readily evaluate, the state of the art of measurements and who are able to apply recent developments in measurement science to identified needs.

The second major distinction is the far more political nature of limit standards. In environmental, safety, and health areas, for example, if an agency desires to avoid playing a purely responsive role with other agencies in the establishment of limits, the agency must have independent technical resources to develop independent data. The distinction between the two types of resources, internal and other agency, must be preserved in the generation of a technical basis for its "limits" and for "compliance measurement". But the danger of agency loss of technical independence is more severe in the "limit" case than in the "compliance measurement" case.

On the other hand, if the agency's own data are to be viewed as independent of "technology" bias, the distinction must also be preserved between ES\&H programs and technology development programs. Credibility of ES\&ll standards will depend on the validity of the data presented: 
One additional technical service is required to support both "Limit" standards development and "Compliance Measurement" standards development: statistics. The general statistics that are needed to support research and development are well established in concept. The statistics needed for regulatory compliance, by contrast, have not been developed in a generally accepted manner and will require special attention if the sampling procedures used for compliance are not to be open to serious question. (11) Once this development has been performed in a satisfactory manner, it will not have to be repeated.

\section{System Tracking}

Two mechanical activities will be required to support institutional standards development. The first is the establishment of an institutional memory, so that information required to establish priorities, which may be cumulative, can be collected and evaluated in an effective manner. The second is the tracking of the progress of each standard through the stages of intra-agency development.

The impact of a given potential standard, e.g., for a specific chemical emission, may not be sufficient to justify the cost of development. However, after the same issue has been identified in a number of areas as important, the strength of the total justification will increase to the point that standards development should be undertaken. Therefore, a system will be needed to accumulate this justification and to trigger the standards development at the appropriate stage. 
Once the development process has started, it will then be important to track the development through each of the approximately 350 stages involved for an anticipated standard from start to finish. Such tracking will also assist the judgments required to determine which stages can be bypassed without sacrifice of the integrity of resulting standards.

VI. AGENCY STRATEGIES FOR THE PROVISION OF ESSENTIAL FUNCTIONS

\section{A. Provision of National Functions}

Two of the four necessary national functions are already being provided: consensus generation and specification writing. During the development of individual standards, an agency focus for these functions will be required, and a specific focus must necessarily be created for each standard. This focus will consist largely of technology division activity. Systematic assurance that broader agency concerns are also being incorporated can be provided through the energy standards management function if it is appropriately structured.

The other two national functions, standards document information and institutional interaction, are not now being generally provided in a manner that will meet agency and company needs. Agencies will, therefore, need to strengthen existing external institutions or to 
create new ones. In both cases, there is no need to provide for the execution of these functions internally. However, without agency support, the functions will not be provided in suitable form.

\section{B. Provision of Agency Functions}

\section{Coordination}

The three agency standards coordination functions, management of standards development, priority establishment, and technical decision, are not now usually provided in a systematic way. These are intrinsically internal cross-cut functions and cannot be contracted out. New agency institutions will be called for or existing ones must be charged with the responsibility to provide for each function in a systematic way if agencies are to meet the new pressures on them for the timely development of standard specifications.

2. Support

Provision of the three support functions, technical support for limit standards, technical support for compliance measurement standards, and system tracking can in principle be provided either internally or on contract. In each case technical expertise is an essential requirement. 
Technical support for limit standards will require primarily biologists and structural engineers. Technical support for compliance measurement standards will require physical measurement scientists and engineers. Systems tracking will require management systems specialists and probably computer systems engineers.

\section{Summary}

It is clear that the four essential national functions are broader than any single mission agency. However, they will require strong agency support if they are to be executed effecively. Three of the six agency functions provide intra-agency coordination and must be established internally to each sirongly affected agency. The remaining three agency functions provide broad support to the entire agency participation in standards development. While they can be located either internally or externally depending on the relative availability of personnel and funding, as well as agency preferences, they must be funded by each agency with the necessity to arrive at independent conclusions .

\section{CONCLUSIONS}

The growing desire to anticipate needs for technological standard specifications and measurements represents a transformation from a 
passive role to an active role for such standards. The implementation of an active role by an agency requires new agency approaches. These approaches will need to take full advantage of existing voluntary standards and specification writing organizations. To support them, eight other functions are essential; two national and six departmental. The two national functions would appropriately be established outside of an agency but with agency support. Three of the six agency functions need necessarily to be established within the agency. The remaining three are support functions that can be provided either internally or externally. A specific plan for provision of all functions has already been prepared (12). 


\section{ACKNOWLEDGEMENT}

A number of DoE and NBS colleagues have contributed actively and extensively to development of the ideas in this report. In the Department of Energy, the assistance of George Dix and Robert Poe was essential to the general form and detailed presentation of the planning. At the National Bureau of Standards, the guidance and encouragement of Howard Sorrows and Wayne Cassatt were essential to the entire effort. Extensive conversations with John Wachtman, Jr., Elio Passaglia, James Leiss, and Jack Snell also played an important role at critical junctures in the thinking. The author, however, is entirely responsible for any deficiencies in the logic or conclusions that may be formed. 


\section{REFERENCES}

(1) 95 th Congress, U. S. House of Representatives, Committee on Science and Technology, Subcommittee on the Environment and the Atmosphere Hearing No. 7, March 1, 1977, p. 5.

(2) Op. Cit. p. 211

(3) 0 p. Cit. p. 1147

(4) In some areas, notably in building, the word "standard" refers to a voluntary standard, a standard without official standing, while the word "code" refers to a standard that has official standing. In the present document the word, standard, is used generally for all codes and standards for performance or design practice.

(5) A third form of acceptance is a de facto acceptance, such as that provided by the dominance of one company in a market. An example is the IBM computer card format. This type of acceptance is necessarily not a major factor for anticipated standards.

(6) Jordan Baruch, testimony before joint U.S. Senate and House of Representatives Science Subcommittee hearings, 14 February 1978. 
(7) N. Bruce Hannay, ibid.

(8) Samuel Etris, ASTM, private communication.

(9) James Gruhl, Review of Methods for Assessing the Carcinogenic Hazards from Coal Using Energy Technologies, MIT Report EZ 76015, NTIS No. PB $270682(1976)$.

(10) John Crawford, Sr., DoE, private communication.

(11) Joan Rosenblatt, NBS, private communication.

(12) U.S. NBS Energy Standards Planning and Coordination Task Force: Plan for the Development of Environmental Safety and Health Standards, September 1977. Report to the ERDA Division of Operational and Environmental Safety. 
NBS-114A (REV. 9.78)

U.S. DEPT. OF COMM.

BIBLIOGRAPHIC DATA

SHEET

1. PUBLICATION OR REPORT NO.

NBSIR $\quad 79-1703$

4. TITLE AND SUBTITLE

The Timely Development of Environmental, Safety, and Health Standards for Energy Technologies

5. Publication Date

January 1979

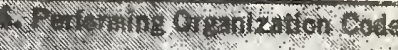

8. Performing Organ Report No.

NBSIR 79-1703

Bruce W. Steiner

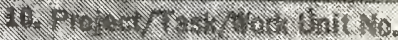

9. PERFORMING ORGANIZATION NAME AND ADDRESS

NATIONAL BUREAU OF STANDARDS

DEPARTMENT OF COMMERCE

WASHINGTON, DC 20234

12. SPONSORING ORGANIZATION NAME AND COMPLETE ADDRESS (Streot, City, State, zIP)

National Bureau of Standards

Department of Commerce

Washington, D.C. 20234

15. SUPPLEMENTARY NOTES

Document describes a computer program; SF-185, FIPS Software Summary, is attached.

16. ABSTRACT (A 200-word or less factual summary of most significant information. If document includes a significant bibliography or litorature survoy, mention it hero.)

The Division of Operational and Environmental Safety (OES) was established in the spring of 1977 as a division of the former Energy Research and Development Administration. As one of its first tasks, OES commissioned the National Bureau of Standards to develop a comprehensive plan for the development of non-nuclear energy-related environmental, safety, and health standards for the Department of Energy. The objective was to provide assurance that the expolitation of new energy technologies by the private sector would not be hindered by the absence in the private sector of (1) all necessary environmental, safety, and health standards; or (2) the ability to comply with them. A detailed plan was submitted to the Division in September 1977.

During the preparation of that report it became clear that the effort commissioned by the OES was representative of a broad transformation with great significance for the standards development process in the United States. The present report consists of a paper describing that transformation in the role of standards, its significance, and the broad implications.

17. KEY WORDS (six to twelve entries; alphabetical order; capitalize only the first letter of the first key word unless a proper namo; separated by semicolons)

Energy Standards, Environmental Standards; Safety and Health Standards;

Standards Development

18. AVAILABILITY Xnlimited

For Official Distribution. Do Hot Release to NTIS

Order From Sup. of Doc., U.S. Government Printing Office, Washington, DC 20402, SD Stock No. SN003-003-

[ Order From National Technical Information Service (NTIS), Springfield, VA, 22161

\begin{tabular}{|l|c|}
\hline $\begin{array}{l}\text { 19. SECURITY CLASS } \\
\text { (THIS REPORT) }\end{array}$ & $\begin{array}{c}\text { 21. NO. OF } \\
\text { PRINTED PAGES } \\
\text { UNCLASSIFIED }\end{array}$ \\
\hline $\begin{array}{l}\text { 20. SECURITY CLASS } \\
\text { (THIS PAGE) }\end{array}$ & 38 \\
\hline UNCLASSIFIED & 22. Price \\
\hline
\end{tabular}



